Çukurova Üniversitesi Mühendislik Mimarlık Fakültesi Dergisi, 33(2), ss. 287-296, Haziran 2018

Çukurova University Journal of the Faculty of Engineering and Architecture, 33(2), pp. 287-296, June 2018

\title{
PCB Dairesel Yama Anten Tabanlı Etanol ve Metanol Algılayıcı Tasarımı
}

\author{
Ŏguzhan AKGÖL *1 \\ ${ }^{1}$ İskenderun Teknik Üniversitesi, Mühendislik ve Doğa Bilimleri Fakültesi, Elektrik-Elektronik \\ Mühendisliği Bölümü, Hatay
}

Geliş tarihi: $12.02 .2018 \quad$ Kabul tarihi: 29.06 .2018

\section{$\ddot{\mathbf{O z}}$}

Bu çalışmada, PCB (Printed Circuit Board - Baskı Devre) dairesel mikroşerit anten kullanılarak etanol+su ve metanol+su karışımlarının miktarlarını algılayabilecek bir algılayıcı tasarlanmıştır. Antenin alt zemini üzerinde tam merkezde açılan dairesel bir boşluk ile birlikte sistemin $3 \mathrm{GHz}$ frekansında çalışabilmesi için optimizasyon yapılmış ve bunun sonucunda geometrik değerler elde edilmiştir. Analizler gerçekleştirilirken dairesel boşluğa, alt iletken yapıya temas etmeden sıvı karışım numunesinin yerleştirilmesi sağlanmış ve rezonans frekansının değişiminin test altındaki numunelerin karışım yüzdeleriyle ilişkisi ortaya konmuştur. Rezonans frekansı etanol su karışımı için $44 \mathrm{MHz}$ 'lik bir algılama bandı sunmakta ve bu aralık metanol su karışımı için yaklaşık $38 \mathrm{MHz}$ civarında olmaktadır. Rezonans frekanslarında oluşan değişimler doğrusala çok yakın olup, hem etanol hem de metanol karışımlarının yüzdelerini çok yüksek hassasiyetle ve gerçek zamanlı olarak belirlemeye imkan sağlamaktadır. Tasarlanan anten ve algılayıcı yapı hem düşük profile, düşük maliyete sahip olup hem de yüksek hassasiyetli ve eş zamanlı ölçüm kapasitesine sahiptir.

Anahtar Kelimeler: Anten biyo-alg1layı1c1, Dairesel anten, Etanol ve metanol algılama, PCB yama anten, Anten tabanlı sensör

\section{PCB Circular Patch Antenna Based Ethanol and Methanol Sensor Design}

\begin{abstract}
In this study, a sensor that can distinguish ethanol+water and methanol+water mixture amount by using PCB (Printed Circuit Board) circular microstrip antenna is designed. On the ground plane of the antenna, a circular slot was made at the center and it was optimized so that the proposed sensor can work at $\mathrm{f}=3 \mathrm{GHz}$ frequency and the geometrical dimensions are calculated accordingly. While performing the analysis, the placement of the liquid mixture is arranged so that the sample under test does not touch to the ground plane and the correlation between the percentages of the mixtures with the changes in the resonance frequency is determined. The resonance frequency shifts provide a frequency range of $44 \mathrm{MHz}$ and this range is about $38 \mathrm{MHz}$ for methanol mixtures. The changes observed in the resonance frequency
\end{abstract}

*Sorumlu yazar (Corresponding author): Oğuzhan AKGÖL, oguzhan.akgol@iste.edu.tr 
are very close to linear changes which allow the determination of the percentages of both ethanol and methanol mixtures with very high precision and in real time. The designed antenna and sensor structure has low profile, low cost and also the capacity of real-time and very precise measurement.

Keywords: Antenna bio-sensor, Circular patch antenna, Ethanol and methanol sensing, PCP patch antenna, Antenna based sensor

\section{GíRiș}

Algılayıcı (Sensör) uygulamaları her zaman bilim adamlarının ilgi odağı olmuştur. Bu yüzden gelişen teknoloji ile birlikte, daha hassas ve farklı alanlarda kullanılabilecek algilayıcılar hem bilim adamları tarafindan hem de mühendisler tarafindan çalışılmaktadır. Metamalzeme tabanlı mikrodalga sensörler ethanol oranı tespitinde $3-5 \mathrm{GHz}$ aralığında yakın zamanda kullanılmıştır [1]. RF tabanlı mikrodalga sensörler ayrıca kutuplu sıvıların belirlenmesi için de denenmiştir [2]. Ayrıca, antenlerde dielektrik özelliğinin tespiti amacı ile kullanımı da yaygındır [3]. Su-etanol bileşimi oran tespitinde mikroşerit hat tabanlı kimyasal sensörler kullanılmıştır [7]. Kullanılan sensörler eşleştirilmiş özellikli ya da ayrı halka özelliğine sahip metamalzemelerdir [8]. Ayrıca, yine siv1 etanol tespitinde $70 \mathrm{MHz}$ hassasiyetli 8 modlu antenler minyatür kimyasal sensör olarak ele alınmıştır [9]. Ayrık halka rezonatörleri ile yüklü yamaların etanol tespitinde kullanıldığ çalı̧̧mada kalite faktörü tespiti denenmiştir [12]. $\mathrm{Bu}$ çalışmada $\% 10$ hassasiyet sağlanmıştır. Yine etanol ve metanolün tespiti amacı ile metamalzeme tabanlı kimyasal sensörler 230 kalite faktörü ile gerçekleştirilmiştir [10]. Etanol miktarı belirlenmesi amacı ile metamalzeme tabanlı sinyal emicilerde kullanılmışı̧ı [11].

Antenlerin çok değişik alanlarda kullanımı mevcut olup algılayıcı olarak kullanımında, gerçek zamanlı ve hassas ölçüm gibi çok önemli avantajlar sunmaktadır. $\mathrm{Bu}$ çalışmada farklı elektriksel geçirgenlik (E) ve kayıp tanjant (losstangent) değerlerine sahip çeşitli su+etanol ve su+metanol karışımlarının $(\% 0-\% 100) \mathrm{f}=3 \mathrm{GHz}$ frekansında çalışacak şekilde tasarlanan dairesel mikroşerit anten ile algılanması gerçekleştirilmektedir. Tasarlanan anten yapısı küçük boyutlara sahip olma, gerçek zamanlı ve hassas duyarlılığa ve düşük profile sahip olma gibi birçok avantaja sahiptir.

Antenin ön yüzeyinde bir dairesel yama bulunup mikroşerit hat ile ayrık bir porta bağlanmaktadır. Arka yüzeyinde ise bakır kaplı olup merkezinden algılamanın yapılabilmesi için bir dairesel kesinti alınmıştır. Algılanmak istenen karışımın elektromanyetik özelliklerine göre tasarlanan antenin çalışma frekansı doğrusal bir şekilde kaymaktadır. Saçılım parametreleri olarak da bilinen S-Parametrelerinden $S_{11}$ parametresindeki değişim göz önüne alınarak test için bırakılan sıvının karışım miktarının tespiti kolayca gerçekleştirilebilmektedir. Literatürde bio-algolayıcı olarak da bilinen bu tür yapılarla çeşitli algılayıcı çalışmaları sunulmaktadır [4-5]. Bunun yanında antenler çok önemli testlerde mikrodalga sensörleri olarak incelenmiştir. Örneğin, çatlak ve dayanıklılık tespiti [6] bunlardan önemli olanlarından biridir. Bununla birlikte, antenler ile etanol ve metanol karışımlarını birlikte inceleyen ve ayrıştırılmasına yönelik çalışmalar fazla değildir ve sunulan model oldukça hassas bir ölçüm sunmaktadır.

\section{MATERYAL VE METOT}

Algılayıcı anten yapısının tasarımı için geri dönüşüm kaybı $\left(\mathrm{S}_{11}\right)$ parametresinin istenilen frekansta $(\mathrm{f}=3 \mathrm{GHz})$ rezonansa girmesi sağlanmıştır. $\mathrm{Bu}$ frekansta iyi bir uzak alan yayılımı gösterebilecek dairesel bir yap1 tercih edilmiş ve geometrik parametreleri buna uygun optimize edilmiştir. Şekil 1'de antenin ön ve arka yüzeyinin yapısı görünmektedir.

Antenin analizinde ayrık port kullanılmış ve SMA konektörlere uygun bir bağlantı göz önünde bulundurulmuştur. Böylece pratik uygulamalarda yapının kullanılması daha kolay, düşük boyutlu ve 
az maliyetli olacaktır. Şekilden görüldüğü gibi antenin yayılım yapan yama kısmı dairesel şeklinde ve optimizasyon sonucu çapı $\mathrm{D}=24 \mathrm{~mm}$ olarak alınmıştır. Beslenme için kullanılan mikroşerit hattın ise $1 \mathrm{~mm}$ kalınlıkta olması gerektiği bulunmuştur. Tasarımda $35 \mu \mathrm{m}$ kalınlığında ve $5,80001 \times 10^{7}$ iletkenliğe sahip bakır cinsi metal tercih edilmiştir. Ara yapı için ise 1,6 mm kalınlığında 0,02 kayıp tanjant ve 4,30 bağıl geçirgenliğe sahip FR4 malzemesi seçilmiştir. $9 \mathrm{~mm}$ çapındaki numunenin yerleştirilebilmesi için antenin arka tarafında 10 mm çapında bir boşluk açılmıştır.

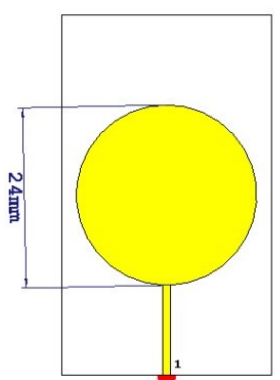

(a)

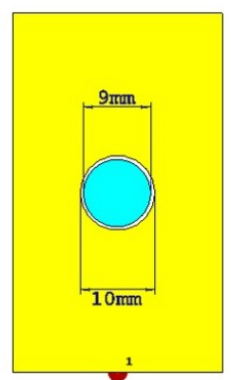

(b)
Şekil 1. PCB mikroşerit dairesel yama anteninin detaylı ön (a) ve Arka Görünümü (b)

Tasarlanan algılayıcı çalışmasının analizi için FIT (Finite-Integration Technique) tabanlı elektromanyetik simülasyon programı kullanılmıştır. Simülasyon içinde bir tane ayrık port tanımlanmış ve geri dönüşüm kayıplarının rezonans değişimleri incelenmiştir. Optimize edilen antenin geri dönüş kaybı olarak da bilinen $\mathrm{S}_{11}$ parametresinin grafiği Şekil 2'de verilmiştir.

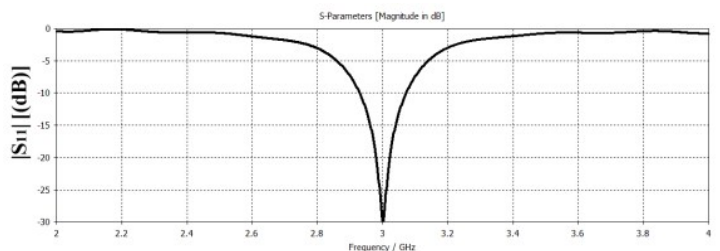

Şekil 2. Antenin geri dönüş kaybı grafiği $\left(\mathrm{S}_{11}\right)$

Görüleceği üzere, tasarlanan yama anten $3 \mathrm{GHz}$ frekansında rezonansa girmekte ve en fazla enerji iletimi bu frekansta gerçekleşmektedir. Anten endüstrisinde kullanım alanına göre $S_{11}$ değerinin
$-10 \mathrm{~dB}$ veya $-15 \mathrm{~dB}$ değerinin altında olması istenmektedir. Şekilden görüldüğü gibi antenin çalışma frekansındaki $S_{11}$ değeri yaklaşık $-30 \mathrm{~dB}$ seviyesindedir ve bu seviye antenin istenen noktada iyi yayılım yaptığını göstermektedir. Eğer $-10 \mathrm{~dB}$ seviyesi referans alınırsa, antenin bant genişliği yaklaşı $143 \mathrm{MHz}$ civarında oluşmuştur.

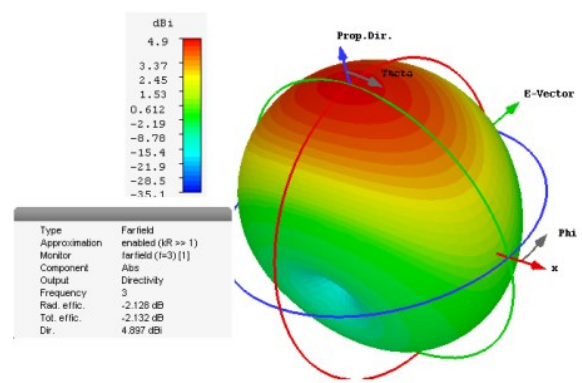

(a)

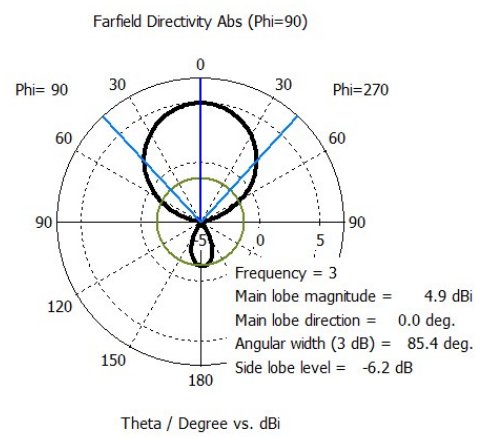

(b)

Şekil 3. Dairesel yama antenin uzak alan 1şımasının üç boyutlu (a) ve Polar gösterimi (b)

Tasarlanan antenin sensör özelliğinin dışında da iyi yayılım yaptığını göstermek için uzak alan 1şımasına da bakılması gerekmektedir. Uzak alan ışımasının üç boyutlu ve polar gösterimleri sırasıyla Şekil 3(a) ve (b)'de verilmiştir. Bu şekillerden görüleceği gibi yayılım ana lob üzerinde yoğunlaşmıştır ve yan loblar yok denecek kadar azdır ve arka lob ise çok düşük seviyededir. Daha sonra yapılacak çalışmalarda, etanol, metanol veya başka sıvıların bulunduğu sıv1 sensörleri için veya hareket, basınç ve denge sensörleri gibi uygulamalar için bu parametrelerin değișimleri de kontrol edilip, algılama için kullanılabilir. Diğer bir bakış açısıyla bakılırsa, 
sensör katmanına bırakılacak malzemeyle antenin temel parametrelerinin iyileştirilmesi veya arzu edilen seviyeye getirilmesi sağlanabilir.

Önerilen antenin polar görüntüsüne bakılırsa antenimizin yönlülüğünün izotropik antene kıyasla $4,9 \mathrm{~dB}$, sşıma açısının $85,4^{\circ}$ ve ana lob yönünün istenildiği gibi $0^{\circ}$ noktasında olduğu görülebilir. Ayrıca, arka lobun seviyesinin düşük seviyede ve $-6,2 \mathrm{~dB}$ değerinde olduğu görülmektedir. Anten endüstrisinde önemli parametrelerden olan ön-arka lob oranının bu değerlerin toplamı şeklinde $4,9+6,2=11,1 \mathrm{~dB}$ 'lik iyi sayılabilecek bir değere sahip olduğu görülmektedir. Arka lobun biraz yüksek olmasının sebebi ise arka kısımda algılama işlemini yapmak için açtığımız oyuğun varlığından kaynaklanmaktadır. Burada bulunan bakır plaka normal şartlarda gelen dalgayı tam yansitarak 1şımanın yoğunluğunu daha fazla artıracak ve arka lobun değerini daha düşük seviyelere çekecektir. Fakat algılayıcı olarak kullanılması planlanan anten yapısında arka lob ve kazanç değerlerinden ziyade test altındaki numunenin karışım oranına göre rezonans değerinin değişimi gözlemlenmektedir.

Tasarlandığı üzere, dairesel yama antenin arka yüzeyinde oluşturulan oyuğa test edilecek karışım yerleștirilmektedir. Yüzey akım dağılımların gösterildiği Şekil 4'ten de görüldüğü gibi bu oyuk oldukça hassas davranmakta ve bu oyuk etrafinda yüzey akımları yoğun bir biçimde oluşmaktadır. PCB tekniğiyle tasarlanan anten düşük profil ve düşük maliyete sahip olduğundan oldukça kolay ve mevcut sistemlere de uygulanabilecek pahalı olmayan bir uygulama imkanı sağlamaktadır.

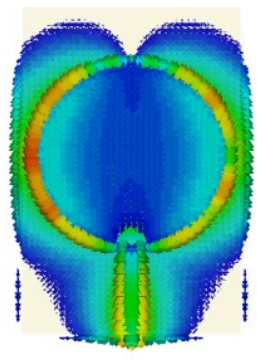

(a)

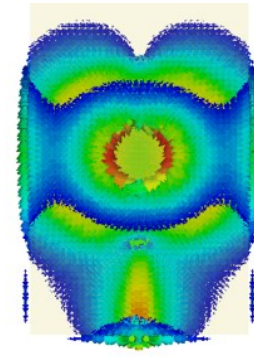

(b)
Şekil 4. Antenin ön (a) ve arka (b) yüzeyindeki akım dağılımları
Sunulan dairesel tabanlı anten algılayıcının amacı saf su içine katılan etanol ve metanol miktarlarının tespitini yapmaktır. Tasarlanan algilayıcının sıv1 karışım miktarını algılama kapasitesini kontrol etmek için farklı oranlardaki etanol ve metanol ve su karışımları kullanılmıştır. Dikkatlice oluşturulan bu karışımların dielektrik sabitlerini $(\varepsilon)$ ve kayıp tanjant değerlerini bulmak için laboratuvarımızda bulunan Agilent 85070 E dielektrik probe ve bu aparatın bağlı bulunduğu PNA-L Agilent vektör network analizör cihazı (VNA) kullanılmıştır. Bu analizörün çalışma bandı $43,5 \mathrm{GHz}$ frekansına kadar olan geniş bir spektrumu kapsamaktadır.

Dielektrik prob seti kullanılmadan önce elektromanyetik özellikleri bilinen ve sistemde kayitlı olan saf su, hava ve kalibrasyon setinde bulunan kisa devre aparatı ile sistem kalibre edilmiş ve saf su ile ilk ölçüm alınarak kalibrasyon kontrol edilmiştir. Tüm ön hazırlıklar tamamlandıktan sonra yapılan ölçümler sonucunda bulunan değerler Çizelge 1 ve Çizelge 2'de verilmiştir. Çizelge 1 ve 2 'den görüleceği gibi dielektrik katsayısının gerçel kısmı seçilen frekansta neredeyse mükemmel oranda doğrusal değişmektedir. Tasarım için $\mathrm{f}=3 \mathrm{GHz}$ 'lik çalışma frekansının seçilmesinin önemli bir sebebi de budur.

Çizelge 1. $3 \mathrm{GHz}$ frekansında etanol içeriğine bağlı olarak laboratuvarda ölçülen dielektrik ve kayıp tanjant $(\tan \delta)$ değerleri

\begin{tabular}{|c|c|c|c|}
\hline $\begin{array}{c}\text { Etanol } \\
\text { İçeriği (\%) }\end{array}$ & $\varepsilon^{\prime}$ & $\varepsilon^{\prime \prime}$ & $\tan \delta$ \\
\hline 0 (Saf Su) & 78,65 & 11,16 & 0,141 \\
\hline 10 & 74,15 & 10,52 & 0,141 \\
\hline 20 & 70,32 & 9,99 & 0,142 \\
\hline 30 & 64,8 & 8,91 & 0,137 \\
\hline 40 & 55,17 & 8,74 & 0,158 \\
\hline 50 & 48,69 & 8,09 & 0,166 \\
\hline 60 & 41,5 & 7,56 & 0,182 \\
\hline 70 & 36,21 & 7,12 & 0,196 \\
\hline 80 & 29,07 & 6,89 & 0,237 \\
\hline 90 & 18,17 & 6,23 & 0,343 \\
\hline 100 & 10,14 & 5,97 & 0,588 \\
\hline
\end{tabular}


Çizelge 2. $3 \mathrm{GHz}$ frekansında metanol içeriğine bağlı olarak laboratuvarda ölçülen dielektrik ve kayıp tanjant $(\tan \delta)$ değerleri

\begin{tabular}{|c|c|c|c|}
\hline $\begin{array}{c}\text { Metanol } \\
\text { İçeriği (\%) }\end{array}$ & $\varepsilon^{\prime}$ & $\varepsilon^{\prime \prime}$ & $\tan \delta$ \\
\hline 0 (Saf Su) & 78,65 & 11,16 & 0,141 \\
\hline 10 & 66,90 & 7,42 & 0,110 \\
\hline 20 & 62,70 & 8,58 & 0,136 \\
\hline 30 & 58,40 & 10,10 & 0,172 \\
\hline 40 & 54,80 & 10,20 & 0,186 \\
\hline 50 & 49,10 & 14,60 & 0,297 \\
\hline 60 & 42,70 & 15,30 & 0,358 \\
\hline 70 & 38,10 & 15,50 & 0,406 \\
\hline 80 & 30,20 & 15,90 & 0,526 \\
\hline 90 & 25,20 & 15,00 & 0,595 \\
\hline 100 & 20,90 & 12,90 & 0,617 \\
\hline
\end{tabular}

Çizelge 1 ve 2 'de network analizör cihazına bağlı dielektrik prob ile ölçülen çeşitli oranlardaki metanol+saf su ve etanol+saf su karışımlarının dielektrik sabitlerinin değişimi görülmektedir. Kompleks dielektrik sabiti değerleri oda sıcaklığında ölçülmüştür. Çizelge 1 ve 2 hem gerçel kısmı $\left(\varepsilon^{\prime}\right)$, hem sanal kısmı $\left(\varepsilon^{\prime \prime}\right)$ ve her ikisinin oranı olan kayıp tanjant değerlerini $\left(\tan \delta=\varepsilon^{\prime \prime} / \varepsilon^{\prime}\right)$ içermektedir. Burada kayıp tanjant değeri iletim boyunca kaybolan elektromanyetik dalga enerjisini ölçmektedir. $\mathrm{Bu}$ çizelgeler oluşturulurken algılama yapısı vakum seçildiğinde elde edilen çalışma frekansı olan $\mathrm{f}=3 \mathrm{GHz}$ ele alınmıştır. Çizelge 1 ve 2'den görüldüğü üzere, hem etanol hem de metanolün kullanıldığ karışımlarda su oranı düştükçe elektromanyetik geçirgenliğin gerçel değerleri giderek azalmakta buna karşılık kayıp tanjant değerleri ise giderek artmaktadır.

\section{BULGULAR VE TARTIŞMA}

Elde edilen elektromanyetik katsayı değerleri yani dielektrik katsayısı ve kayıp tanjant değerleri kullanılarak simülasyonda yeni malzemeler tanımlanmıştır. Tasarlanan antenin arka kısmında açılan oyuk üzerinde ise silindir tanımlanarak karışımlar test edilmiştir. Etanol ve metanol ile saf su karışım yüzdelerine bağlı olarak algılayıcı tasarımında oluşan rezonans frekansı kaymaları Şekil 5 ve Şekil 6'da gösterilmiştir. Karışımlar hazırlanırken \%10'luk eklemeler yapılmış ve ölçümler buna uygun olarak bulunmuştur. Fakat grafikte karmaşıklığ 1 önlemek için sadece \%20’lik adımlar gösterilmiştir. Tüm karışım numunelerine karşılık gelen sonuçlar Çizelge 3 ve Çizelge 4'te gösterilmiştir.

Etanol ve saf su karıșımının konsantrasyon değişimine karşılık gelen rezonans frekansındaki değişmeler Şekil 5'te görülmektedir. Şekilden görüleceği gibi değişimler doğrusala çok yakın olup toplamda 44 MHz'lik bir algılama bandını kapsamaktadır.

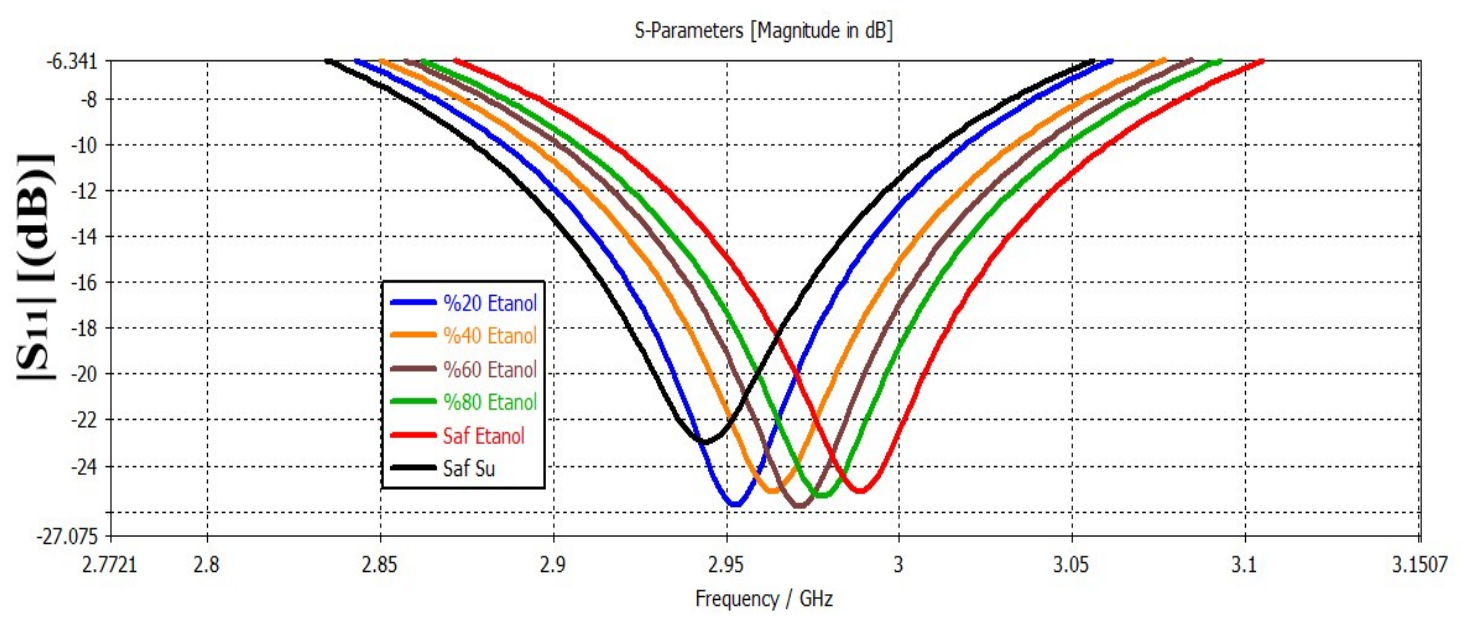

Şekil 5. Saf su ve etanol karışımındaki konsantrasyon yüzdesine bağlı rezonans frekansı değişimleri 


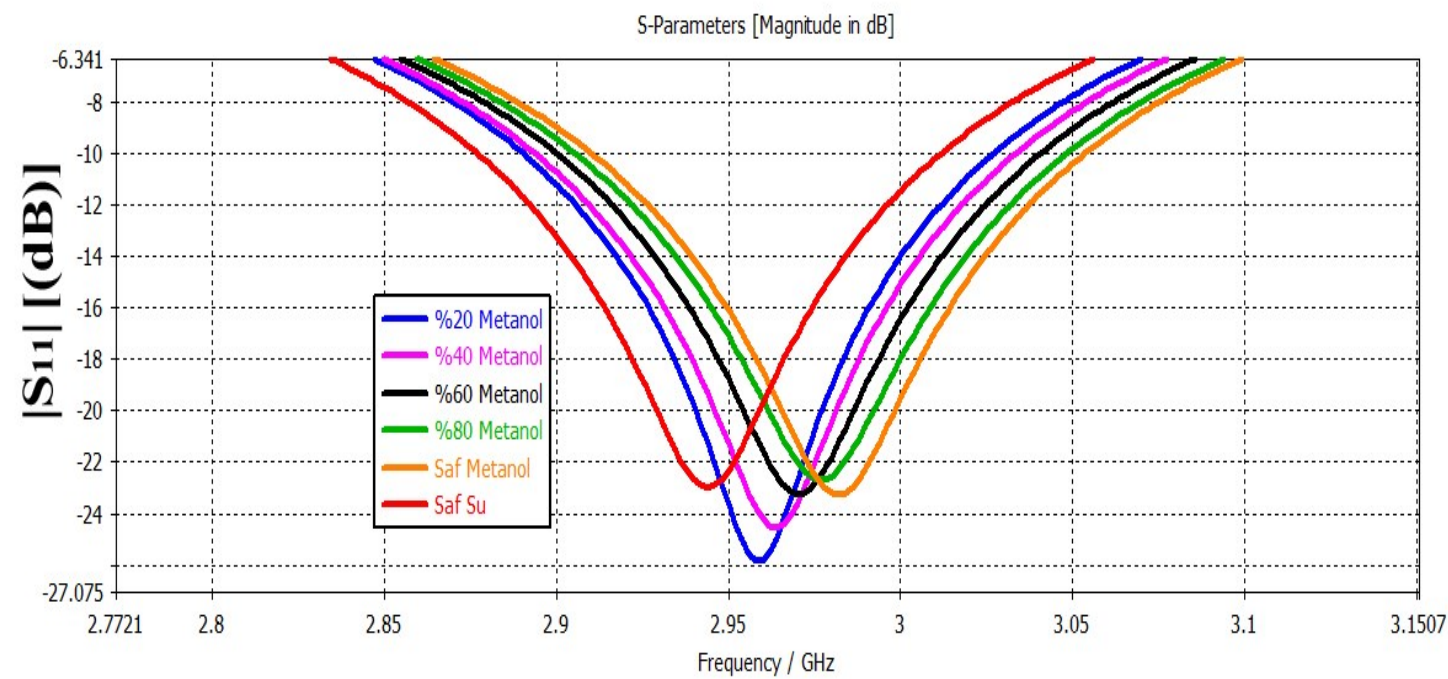

Şekil 6. Saf su ve metanol karışımındaki konsantrasyon yüzdesine bağlı rezonans frekansı değişimleri

Test edilen karışımların ve bunlara karşılık gelen rezonans frekansı değişimleri ve geri dönüşüm değerleri $\left(\mathrm{S}_{11}\right)$ Çizelge 3 ve Çizelge 4'de detaylarıyla verilmiştir. Şekil 5 ve 6'da çizilen değerlere ek olarak her \%10'luk değişime karş11ık gelen değerler bu çizelgelerde bulunmaktadır.

Çizelge 3. Etanol içeriğine bağlı olarak değişen rezonans frekansı ve $S_{11}$ değerleri

\begin{tabular}{|c|c|c|}
\hline $\begin{array}{c}\text { Etanol + Su } \\
\text { Içeriği (\%) }\end{array}$ & $\begin{array}{c}\text { Rezonans Frekans1 } \\
(\mathrm{GHz})\end{array}$ & $\begin{array}{c}\mathrm{S}_{11} \text { Değeri } \\
(\mathrm{dB})\end{array}$ \\
\hline $0(\mathrm{Saf} \mathrm{Su})$ & 2,944 & $-22,970$ \\
\hline 10 & 2,948 & $-24,464$ \\
\hline 20 & 2,952 & $-25,695$ \\
\hline 30 & 2,958 & $-26,596$ \\
\hline 40 & 2,964 & $-25,132$ \\
\hline 50 & 2,968 & $-25,241$ \\
\hline 60 & 2,972 & $-25,769$ \\
\hline 70 & 2,974 & $-25,837$ \\
\hline 80 & 2,978 & $-25,328$ \\
\hline 90 & 2,984 & $-25,365$ \\
\hline 100 (Saf Etanol) & 2,988 & $-25,125$ \\
\hline Hava & 3,002 & $-29,898$ \\
\hline
\end{tabular}

Çizelge 4. Metanol içeriğine bağlı olarak değişen rezonans frekansı ve $\mathrm{S}_{11}$ değerleri

\begin{tabular}{|c|c|c|}
\hline $\begin{array}{c}\text { Metanol }+\mathrm{Su} \\
\text { İçeriği }(\%)\end{array}$ & $\begin{array}{c}\text { Rezonans } \\
\text { Frekans }(\mathrm{GHz})\end{array}$ & $\begin{array}{c}\mathrm{S}_{11} \text { Değeri } \\
(\mathrm{dB})\end{array}$ \\
\hline $0(\mathrm{Saf} \mathrm{Su})$ & 2,944 & $-22,970$ \\
\hline 10 & 2,956 & $-28,020$ \\
\hline 20 & 2,958 & $-25,832$ \\
\hline 30 & 2,962 & $-24,591$ \\
\hline 40 & 2,964 & $-24,536$ \\
\hline 50 & 2,966 & $-23,061$ \\
\hline 60 & 2,970 & $-23,234$ \\
\hline 70 & 2,972 & $-23,187$ \\
\hline 80 & 2,976 & $-22,673$ \\
\hline 90 & 2,980 & $-22,824$ \\
\hline $100($ Saf Metanol) & 2,982 & $-23,281$ \\
\hline Hava & 3,002 & $-29,898$ \\
\hline
\end{tabular}

Sonuçların geniş bantta elde edilmesi ara değerleri kolaylıkla ve çok hassas bir biçimde tahmin edebilme olanağı sağlamaktadır. Saf su kullanıldığında rezonansın 2,944 GHz'de gerçekleştiği ve etanol yüzdesi arttıkça maksimum enerji transferinin gerçekleştiği rezonans frekansının giderek daha yüksek değerlere çıktığ ve saf etanol için $2,988 \mathrm{GHz}$ frekansına eriştiği görülmektedir. Buna karşılık geri dönüş kaybı veya diğer ismiyle $\mathrm{S}_{11}$ saçılım parametresinin genliğinin çok fazla değişmediği de not edilmeye değerdir. 
PCB dairesel mikroşerit yama anten tabanlı sıv1 algılayıcı tasarımı etanol ve saf su karışımında olduğu gibi metanol su karışımında da algılama işlemini başarıyla gerçekleştirmektedir. Metanol ve saf su karışımındaki konsantrasyon oranına bağlı olarak sistemin rezonans frekansındaki değişimler Şekil 6'da verilmiştir. Ölçümler her \%10 değişim için yapılmış olsa da şeklin daha anlaşılır olması için \%20'lik aralıklar seçilmiştir. Şekil 6'dan görüldüğü gibi saf su karışımında $\mathrm{f}=2,944 \mathrm{GHz}$ frekansında oluşan rezonans noktası, saf metanol kullanıldı ğında $\mathrm{f}=2,982 \mathrm{GHz}$ değerine ulaşmış ve yaklaşık 38 MHz'lik bir algılama bandı gözlemlenmiştir.

Literatürde bulunan çalışmaların [4] aksine bu yapının düşük konsantrasyonlarda bile hassas bir ölçüme imkan sağlaması çalışmanın bir başka pozitif yönünü oluşturmaktadır. Çizelge 3 ve 4 incelendiğinde, \%10'luk konsantrasyon değişimlerinde etanol için en az $4 \mathrm{MHz}$ 'lik değişimler gözlenmekte ve bu değişimler metanol için $2 \mathrm{MHz}$ civarında gerçekleşmektedir. Bu değerler, karışım oranı bilinmeyen sıvıların ölçümünde son derece hassas tahmin gücü sağlayacaktır. Buna karşılık, $S_{11}$ değerlerinde genel itibariyle çok fazla bir değişim görülmemektedir. Bunun sonucunda, antenin enerji iletimini sıv1 karışımının çok fazla bozmadığı ve etkin bir şekilde kullanılabileceği söylenebilir.

Seçilen çalışma frekansının uygunluğunu ve bulunan rezonans değerlerinin karışımların konsantrasyonları ile korelasyon içinde olduğunu göstermek için karıșım oranlarına bağlı olarak rezonans frekansı ve dielektrik katsayısı değişimleri hem etanol için (Şekil 7.a.) hem de metanol için (Şekil 7.b) grafik şeklinde verilmiştir. Şekil 7'den görüldüğü gibi hem etanol hem de metanol karışımları için dielektrik katsayısı ve rezonans frekansı arasında güçlü bir bağlantı mevcuttur.

Etanol ve metanol katkılarının sebep olduğu rezonans değişimleri dielektrik sabiti değerleriyle ters orantılı olup aradaki değişimin doğrusal bir değişime çok yakın olduğu Şekil 7'den açıkça görülmektedir. Her bir basamakta oluşan değişimin bize sağladığı aralık ara değerlerin tahmini için yeterlidir ve ileriki çalışmalarda küçük bir eğitim algoritması aracılığıyla bulunan değerlerin kullanılması ile yüksek hassasiyetli tahminlerin yapılması mümkündür. Şekil 7'deki eğrilerin sunduğu değişimler ölçülen karışımdaki yüzdelik katkı miktarlarını verecek büyüklüktedir. Frekansa bağlı olarak elektriksel boyutun bu karışımları algılamaya yetecek kadar küçük olması tasarlanan anten tabanlı algilayıcının hem etanol hem de metanol kullanilarak oluşturulan karışımları algılamada kullanılmaya uygun olduğu görülmektedir. Bu yönden bakılınca da seçilen çalışma frekansının biyo-algılama uygulaması için uygun olduğu söylenebilir.

\section{SONUÇ}

$\mathrm{Bu}$ çalışmada, PCB dairesel yama anten tabanlı Sıvı algılayıcı tasarımı gerçekleştirilmiştir. $\mathrm{Bu}$ sistemin biyokimyasal algılayıcı olarak ve etanol/metanol+su karışımlarından oluşan numunelerin hızlı, gerçek zamanlı ve doğru şekilde algılanması işleminin başarılı bir şekilde gerçekleştirilebileceği gösterilmiştir. Algılayıcının hızı, farklı bir laboratuar ortamına ihtiyaç duyulmadan numune alınan ortamda sonuç vermesini, ayrica uzun ve detaylı kimyasal analizlere ihtiyaç duyulmamasını ifade etmektedir. \%10'luk değişimlerle oluşturulan etanol ve metanol katkılarının su içerisindeki konsantrasyonuna bağlı olarak rezonans frekansının doğrusal bir şekilde değiştiği gösterilmiş ve bu değişimin hassas bir algılama için kullanılabileceği gösterilmiştir. Katkı madde miktarındaki ufak değişimler rezonans frekansında doğrusal değişimlere sebep olacak ve bu kaymalar sayesinde katkının miktarını tespit edilmesi sağlanacaktır. Tasarlanan sistem birçok avantajlar sunmaktadır. Örneğin, PCB (Baskı Devre) tekniği ile tasarlanmış olduğundan düşük maliyet ve profile sahiptir, başka bir aparata gerek duymamaktadır ve daha küçük miktarda numune ile ölçüm alabilmektedir. Bütün bu sonuçlar göz önüne alındığında, tasarlanan anten tabanlı algılayıc1 sisteminin etanol + su ve metanol + su karışımlarını tahmin etmede çok hassas sonuçlar verebileceği ispatlanmış olup başka sıvı karışımları için bu yap1 ve bulunan değerler referans alınarak yeni algılayıcıların geliştirilmesi mümkündür. 


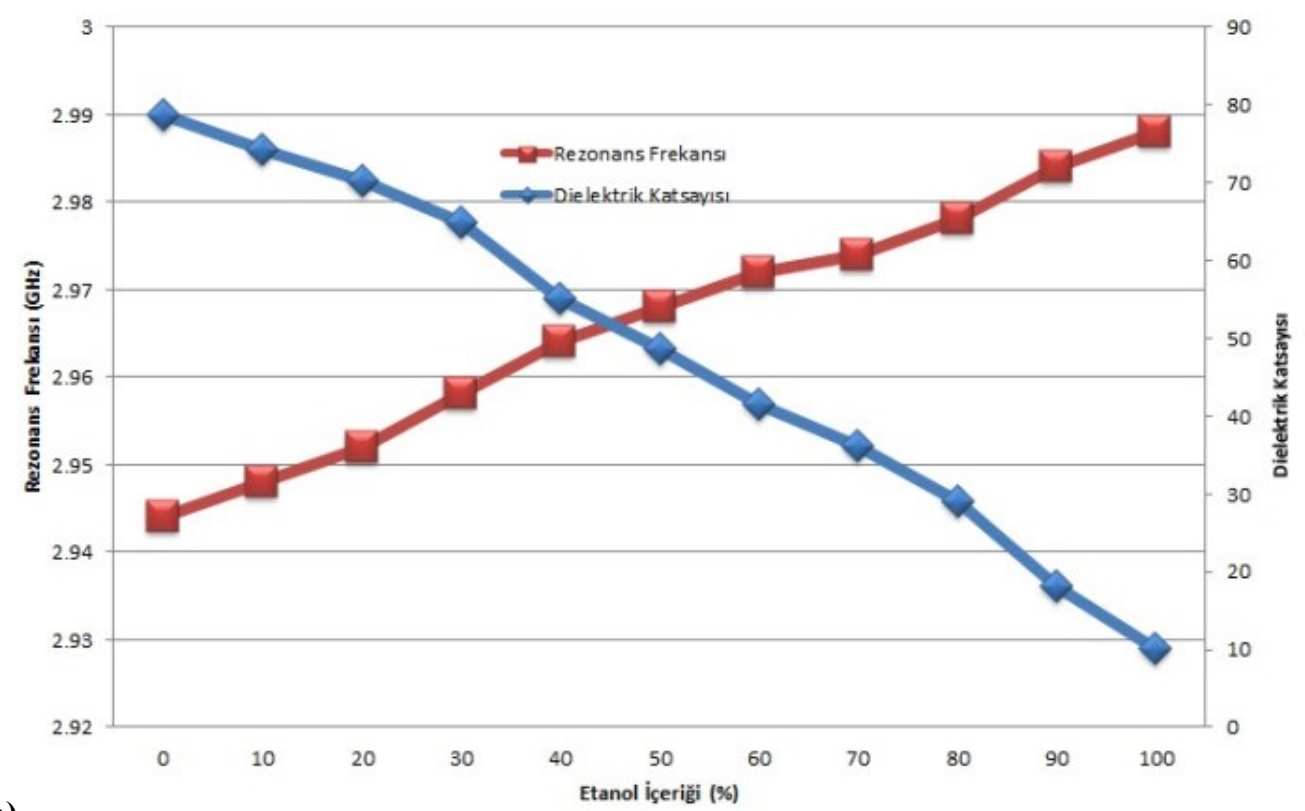

a)

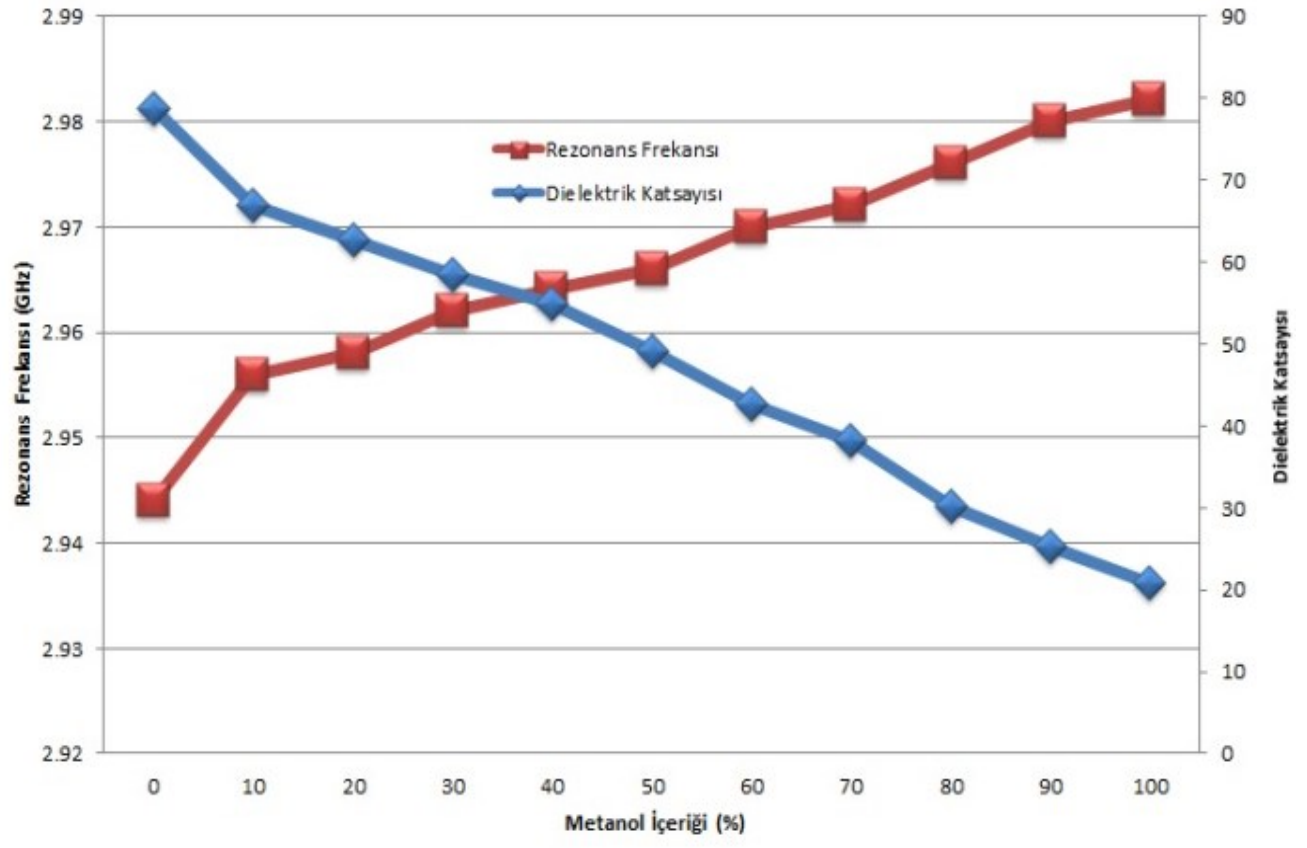

b)

Şekil 7. Rezonans frekansı, dielektrik katsayısı ile Etanol (a) ve metanol (b) konsantrasyonları dağılımları

Her ne kadar etanol ve metanolün oranının belirlenmesine yönelik ayrı ayrı çalışmalar literatürde bulunmasına rağmen, bu çalışma önemli yenilikler içermektedir. İlk olarak literatürde etanol ve metanolün mikrodalga teknikleri ile her ikisinin 
oransal tespitine yönelik çok az sayıda çalışma bulunması, bu çalışmayı farklı kılmaktadır. Ayrıca, bu amacı gerçekleştirmek için anten kullanımı literatürde ilktir. İki sıvının birlikte algılanmasının zorluğu dielektrik katsayılarının birbirlerine çok yakın olmasıdır (Çizelge 3 ve Çizelge 4). Bu yakınlığa rağmen tespit ise çalışmayı önemli kılmaktadır.

\section{KAYNAKLAR}

1. Altintas, O., Aksoy, M., Akgol, O., Unal, E., Karaaslan, M., Sabah, C., 2017. Fluid, Strain and Rotation Sensing Applications by using Metamaterial Based Sensor Journal of the Electrochemical Society, 164: B567-B573.

2. Gregory, A.P., Clarke, R.N., 2006. A Review of RF and Microwave Techniques for Dielectric Measurements on Polar Liquids, IEEE Trans. Dielectr. Insul. 13, 727-743.

3. Akhavan, H.G., Mirshekar-Syahkal, D., 1999. Slot Antennas for Measurement of Properties of Dielectrics at Microwave Frequencies, Antennas and Propagation, 8-11.

4. Chang, F.C., Shiu, J., Yin, Y.Z., Lin, C.W., 2012. A Novel Design of Antenna for Biosensing Applications, IMCS, 407-410.

5. Pal, A.A., Mehta, A., Marhic, M.E., Chan, K.C., Teng, K.S., 2011. Microresonator Antenna for Biosensing Applications, in IET Micro \& Nano Letters, 6(8), 665-667.

6. Yi, X., Cho, C., Cooper, J., Wang, Y., Tentzeris, M.M., Leon, R.T., 2013. Passive Wireless Antenna Sensor for Strain and Crack Sensing-Electromagnetic Modeling, Simulation and Testing, Smart Materials and Structures, 22,085009, 1-17.

7. Ebrahimi, A., Withayachumnankul, W., AlSarawi, S., Abbott, D., 2014. High-Sensitivity Metamaterial-Inspired Sensor for Microfluidic Dielectric Characterization. IEEE Sens. J. 14, 1345-1351.

8. Kim, H.K., Yoo, M., Lim, S., 2015. Novel Ethanol Chemical Sensor using Microfluidic Metamaterial. In Proceedings of the IEEE International Symposium on Antennas and Propagation \& USN National Radio Science
Meeting, Vancouver, BC, Canada, 19-24 July 2015; 1358-1359.

9. Seo, Y., Memon, M.U., Lim, S., 2016. Microfluidic Eighth-mode Substrateintegrated- Waveguide Antenna for Compact Ethanol Chemical Sensor Application. IEEE Trans. Antennas Propag. 64, 3218-3222.

10. Bakir, M., 2017. Electromagnetic-based Microfluidic Sensor Applications. J. Electrochem. Soc. 164, B488-B494.

11. Ling, K., Yoo, M., Su, W., Kim, K., Cook, B., Tentzeris, M.M., Lim, S., 2015. Microfluidic Tunable Inkjet-printed Metamaterial Absorber on Paper. Opt. Express, 23, 110-120.

12. Salim, A., Lim, S., 2016. Complementary Split-ring Resonator-loaded Microfluidic Ethanol Chemical Sensor. Sensors, 16, 1802. 
